Sharif University of Technology
Scientia Iranica
SCIENTIA
IRAN I CA

\title{
Experimental and 3D CFD investigation on energy separation inside a convergent vortex tube air separator
}

\author{
S.E. Rafiee* and M.M. Sadeghiazad \\ Department of Mechanical Engineering, Urmia University of Technology, Urmia, Iran.
}

Received 1 October 2014; received in revised form 3 July 2015; accepted 20 October 2015

\author{
KEYWORDS \\ Experimental \\ approach; \\ Numerical \\ computation; \\ Convergent hot tube; \\ Vortex tube; \\ Convergent angle; \\ Cold orifice diameter.
}

\begin{abstract}
The vortex tube air separator is an invaluable tool which has the ability to separate a high-pressure fluid into the cold and hot fluid streams. The hot tube is the main part of the vortex tube, along which the energy separation procedure happens. This research has been done to analyze the effect of the convergent angle and cold orifice diameter on thermal efficiency of a convergent vortex tube. The convergent hot tube angle varies over the range of 1 to $9 \mathrm{deg}$. Attention to the main angle effect denotes that the highest thermal ability could be achieved at $\beta=5$ deg. Experiments denote that both cooling capability and heating effectiveness reach the highest magnitudes when $D_{\text {Cold }}$ is around $9 \mathrm{~mm}$. After these two stages, the optimized convergent vortex tube is capable of decreasing and rising air temperatures at the cold and the hot sides up to $9.05 \mathrm{~K}(42.89 \%)$ and $10.48 \mathrm{~K}(44.74 \%)$, respectively. A computational fluid dynamics model is employed to predict the performance of the convergent vortex tube. The numerical investigation is done by full 3D steady-state CFD-simulation using FLUENT6.3.26. The results show that the agreement between computation predictions and laboratory measurements is fairly good.

(C) 2016 Sharif University of Technology. All rights reserved.
\end{abstract}

\section{Introduction}

The air separators are typically classified according to the flow direction arrangement. In the Ranque-Hilsch vortex tube (Figure 1(a)), the separated cold and hot fluids leave the hot tube in different directions; but in the parallel ones (Figure 1(b)), the cold and hot streams leave at one side and the exhaust flows are in the same direction. The Ranque-Hilsch VT/vortex tube is an invaluable tool without any moving part, which has the ability to separate a high-pressure fluid into the cold and the hot fluid streams. The inlet injectors are tangenital to the hot tube; thus, this condition leads the entering pressured gas to acquire the circular motion, which gives the tool its name. At one side of injector is a fixed flow restriction named the 'cold exhaust' or 'cold orifice' and at the second

*. Corresponding author. Tel.: +989184733644;

E-mail address: s.e.rafiee@mee.uut.ac.ir (S.E. Rafiee) end of the hot tube, there is a gas controller named the 'hot conical' or 'throttle valve'. These names are derived from the nature of the vortex tube; i.e. the air leaving the tube through the orifice is colder than the entering air while the air leaving through the valve is hotter. When the gas swirls to the center of the vortexchamber, it is expanded and cooled. After occurrence of the energy separation procedure in the vortex tube, the pressured inlet gas stream is separated into two different gas streams including the cold and hot exit gases. The VT systems often experience temperatures or stream separations in the axial direction. The classical or original VT was first invented (accidentally) by a French engineer, Ranque, in 1933. Hilsch [1] was a German physicist, in 1947 who worked on the performance of vortex tube and improved its efficiency. He methodically focused on the effect of the geometrical parameters and the pressure of injectors of the VT on its thermal performance and considered a possible explanation for the thermal separation process inside 


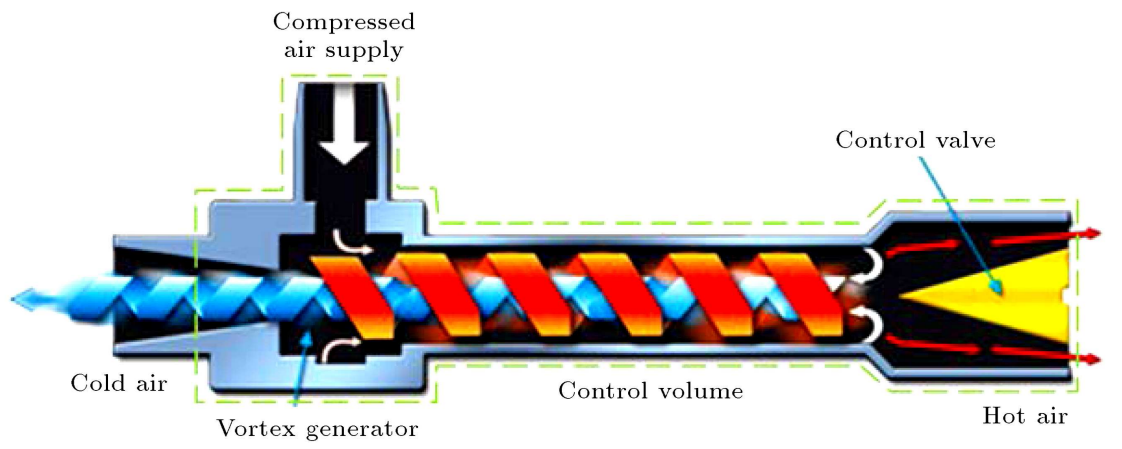

(a)

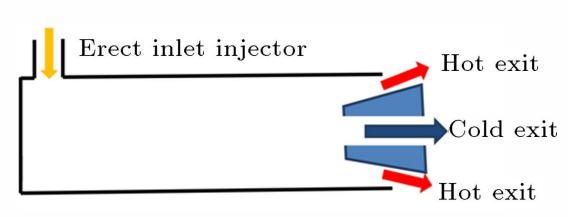

(b)

Figure 1. A schematic drawing of (a) Ranque-Hilsch vortex tube [1], and (b) parallel vortex tube.

the VT. The energy separation enhancement inside the vortex tube has received a lot of attention; thus, several new designs have been applied and investigated in industries/research. These research works can be classified into two categories: computational/numerical and experimental.

\subsection{Experimental studies}

Many scientists have experimentally studied geometrical aspects of vortex tube. They have attempted to demonstrate the conditions in which the highest efficiency is achieved. The thermophysical and geometrical parameters are the significant factors by which the efficiency of VT is affected [2].

Saidi and Valipour [2] classified the affecting factors as the thermophysical factors (such as the pressure of injected gas, type of injected gas, and cold flow ratio, and humidity of injected gas) and the geometrical concepts. Xue and Arjomandi [3] analyzed the effect of rotating flow angle on the efficiency of vortex tube. To find the best rotating angle, they applied several vortex angle generators. It is concluded that using the smaller rotating angle leads to better thermal efficiency of the vortex tube. Dincer et al. [4] have also experimentally focused on the influences of the position, radius, and pressure of injectors, nozzle injector numbers, and mobile plug angle on the air separator cooling capability. The best combination of the geometrical designs is achieved for the plug radius of $2.5 \mathrm{~mm}$ and tip angle of $30 \mathrm{deg}$ when letting the fluid inject into the vortex chamber through 4 injectors. Since the fluid pattern in the vortex tubes is quite complex and fully turbulent, the theory is very weak. The optimum parameters are commonly measured experimentally. The parameters, especially for the vortex tube, rely heavily on the particular manufacturer's design.

A series of complete and successful experimental tests have been performed by Aydın and Baki [5] to determine the effects of pipe length, nozzle injector radius, and control/throttle valve angle on the cooling ability of the VT. Their tests have been done for different air pressures. Based upon their results, better efficiency could be obtained by applying higher inlet pressure. Thus, higher pressure means better cooling ability. They have also noted that the cold mass ratio is an effective parameter influencing the thermal separation phenomenon inside the vortex tube. The best/optimum values for the pipe length, the nozzle injector radius, and the control/throttle valve angle are determined. Rafiee and Sadeghiazad [6,7] conducted computationally and experimentally a comparative investigation into the length of cone at the hot exhaust. As their results, better cooling capability/efficiency could be obtained by applying the optimal cone length. Rafiee and Rahimi [8] designed a vortex chamber with the convergent nozzles. They conducted some numerical and experimental works on the heat transfer and thermal separation phenomenon of the vortex tubes with the convergent nozzles under different inlet pressures at injectors. They found the optimum model using computational methods ( $k-\varepsilon$ turbulence model). Rafiee and Sadeghiazad [9] made an experiment to find the effect of hot conical valve angle on the heat transfer and cooling efficiency of the vortex tube and obtained the best or optimal angle (numerical optimization) with respect to the original case. Rafiee et al. [10] designed a vortex tube with the curved hot tube. They conducted some numerical and experimental works on the heat transfer and thermal separation phenomenon of the vortex tubes with the curved main tube under different inlet pressures at injectors. They found the optimum angle using computational methods (RSM turbulence model). Their tests show that we have an optimum model between $\theta=0$ and $\theta=20^{\circ}$.

\subsection{Numerical studies}

Berber et al. [11] used fuzzy modeling to estimate the flow treatment and thermal performance of a VT. Using numerical methods is more economical than experimental tests. They applied 81 series of experimental data collections to train the numerical algorithm. Several three-dimensional CFD modelings were done by Rafiee and his co-workers [12] by using 
a Computational Fluid Dynamics (CFD) code to optimize the vortex tube factors. The simulated results denote that the vortex chamber radius and the shape of nozzles have different significant effects on the cooling ability of VT. The improvement of cooling capability caused by using the helical nozzles and convergent helical nozzles under the certain operating conditions was computationally predicted. Rafiee et al. [13,14] numerically investigated the effect of working tube radius and the rounding off edge on vortex tube performance and determined the optimum radii. Pourmahmoud et al. [15] also performed a numerical study on working fluid importance in vortex tube applications and their study showed that $\mathrm{CO}_{2}$ was better than $\mathrm{O}_{2}, \mathrm{~N}_{2}$, and air. Rahimi et al. [16] conducted a numerical simulation to analyze the effect of divergent hot tubes on thermal performance of vortex tube. Pourmahmoud et al. [17,18] carried out a numerical study to investigate the flow field and temperature separation phenomenon inside the vortex tube. Rafiee and Sadeghiazad [19] introduced a 3D CFD exergy analysis on the flow separation inside the vortex tube. A precise design of the main/hot tube angle and cold orifice geometries leads to better cooling performance of the convergent VT. A convergent tube can be defined based on using a convergent angle. It should be pointed out that experimental and numerical investigations into optimization of the convergent hot tube angle and the diameter of cold orifice in convergent vortex tubes have not been carried out. In this investigation, the authors believe that choosing an appropriate convergent hot tube angle for the main tube is one of the important physical factors to obtain the highest cooling capability and heating effectiveness.

\section{Basic concepts}

The general concepts and the presentation of results are exactly the same for all of the RHVT (Ranque-Hilsch Vortex Tube) and PVT (Parallel Vortex Tube) vortex tubes. The performance graphs are almost always presented for the hot and cold exhaust temperature drops $\left(\Delta T_{\text {hot }}\right.$ and $\left.\Delta T_{\text {cold }}\right)$. The basic independent input is taken to be the inlet temperature or pressure (in $\mathrm{K}$ or $\mathrm{M} / \mathrm{kPa}$ ). The dependent values or "output" are taken to be the hot and cold exhaust temperature drops $\left(\Delta T_{\text {hot }}\right.$ and $\Delta T_{\text {cold }}$ ) and efficiency $(\eta)$. These concepts can be presented or defined as follows:

$$
\begin{aligned}
& \Delta T_{\text {cold }}=T_{\text {inlet }}-T_{\text {cold }}, \\
& \Delta T_{\text {hot }}=T_{\text {hot }}-T_{\text {inlet }} .
\end{aligned}
$$

In the entire vortex tubes (PVT/RHVT), a throttle valve at the hot side manages the fluid streams. Here, a fundamental physical concept should be remembered as the cold flow ratio. This factor can be given as:

$$
\frac{\text { The rate of cold mass flow }\left(\dot{m}_{\text {cold }}\right)}{\text { The rate of inlet mass flow }\left(\dot{m}_{\text {inlet }}\right)}=\alpha \text {. }
$$

The isentropic approximations are usual in the compressible-flow theory. Isentropic efficiency is given by:

$$
\eta_{i s}=\frac{\Delta T_{c}}{\Delta T_{i s}}=\frac{T_{i}-T_{c}}{T_{i}-T_{i s}}=\frac{T_{i}-T_{c}}{T_{i}\left[1-\left(\frac{P_{a t m}}{P_{i}}\right)^{\frac{\gamma-1}{\gamma}}\right]}
$$

where, $\Delta T_{i s}, \Delta T_{c}, P_{i}$, and $P_{a t m}$ denote the isentropic temperature drop, cold temperature drop, pressure inlet, and ambient pressure, respectively.

\section{Experimental setup and error analysis}

The specific values of the geometrical parameters of CVT (Convergent Vortex Tube) are presented in Table 1 for different convergent vortex tubes. In order to find out the effect of convergent main tube on vortex tube cooling or heating efficiency, some experimental studies were carried out. The experimental set up/tests and the measurement methods are explained in this part. Figure 2 shows the sketch of the convergent VT system. The experimental setup is sketched schematically in Figure 3. Since the air separator (vortex tube) works with no source of heat and work, the thermal process (energy separation process) is driven only by the high-pressure fluid injected into the inlet injector (nozzle). The high-pressure air is directed from the air pipe line into the vortex tube injectors and it enters through the nozzle generator slats. The high-speed air creates a vortex stream in the generator chamber. This swirl flow is divided into two streams due to

Table 1. Geometrical factors of convergent VT which is evaluated in tests.

\begin{tabular}{ll}
\hline Number of injectors & 4 \\
Cold orifice diameter & $7.5,8,8.5,9$, and $9.5 \mathrm{~mm}$ \\
Angle of convergent hot tube & $0,1,3,5,7$, and $9 \mathrm{deg}$ \\
Length of convergent hot tube & $185 \mathrm{~mm}$ \\
Conical valve & Truncated cone \\
Nozzle section & $1.3 \times 1.4 \mathrm{~mm}$ \\
\hline
\end{tabular}




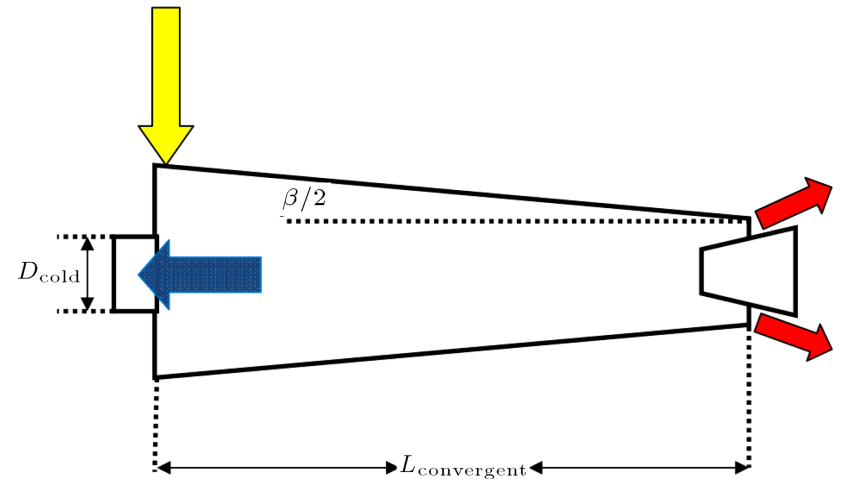

Figure 2. A schematic drawing of the convergent vortex tube.

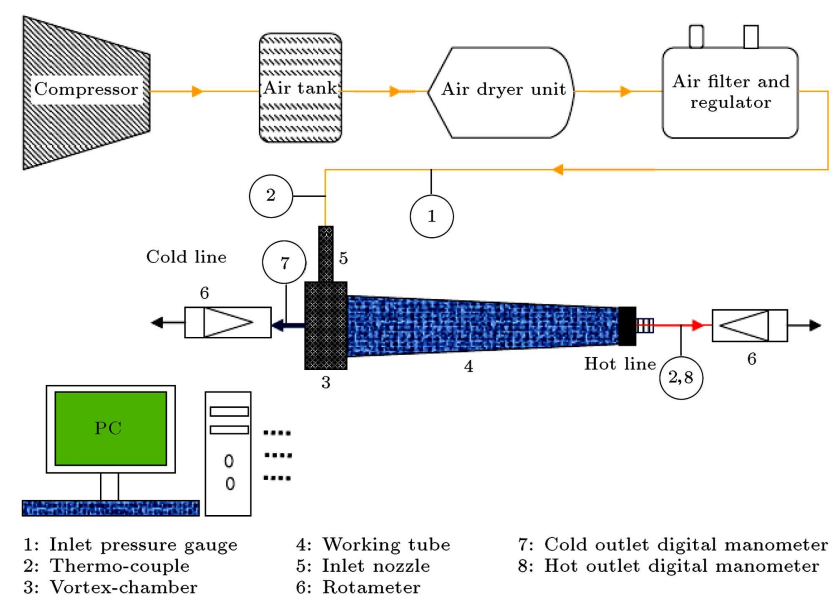

Figure 3. Schematic drawing of the experimental setup.

the thermal separation effect/phenomenon. The cold air leaves the convergent vortex tube from one end side (axis region or the cold orifice), while the hot air leaves the vortex tube through a channel in the outer part. The inlet pressure at injectors was controlled by a special pressure controller or a regulator and the cold flow fraction was controlled by a valve. The temperatures of the air at the injectors (to determine the air temperature/pressure, a PT 100 temperature sensor and a pressure transmitter were adjusted at the gates) or the hot/cold end outlet were determined using PT100 thermal resistance. Two rotameters were used to measure the mass flow rate of both exhausts and each rotameter was calibrated in its working range of temperature respectively. The pressure of injected air at the inlet injector was kept at $0.65 \mathrm{MPa}$ by adjusting the valve whenever the condition changed. The valve at the cold line was initially closed and turned up slowly. The results were taken when the operating condition and the cold mass fraction remained stable. Temperature drop initially occurred in the cold side (expansion part) of the main tube and extended to the cold orifice with action of the valve. It has been confirmed that for a common vortex tube, as cold fraction rises up, the cold-side temperature first shows a trend of decrease and then increases. Also, the lowest cold-side temperature is usually gained within the cold flow ratio range of 0.2 to 0.35 . In this study, the lowest cold-side temperature occurred at 0.23-0.35. In this study, six hot tubes with six convergent angles of $\beta=0,1,3,5,7$, and $9 \mathrm{deg}$ are considered. Also, five different cold orifices of $7.5,8,8.5,9$, and $9.5 \mathrm{~mm}$ for the Cold Diameter have been used. The convergent length is fixed at $185 \mathrm{~mm}$. The geometrical factors are listed in Table 1. The error analyses of pressure and temperature measurements are described in this part. The maximal errors in pressure and temperature were presented by applying the procedure illustrated by Moffat [20]. The mentioned errors were determined with the minimum magnitudes of accuracy of the instrument and the output. If a considered value $k$ relies on independent variables such as $z_{i}$, then the error in the value of $k$ is calculated by:

$$
\frac{\partial k}{k}=\sqrt{\sum_{1}^{n}\left(\frac{\partial z_{i}}{z_{i}}\right)^{2}} .
$$

In this equation, $\partial z_{i} / z_{i}$ is the error in the independent term, $\partial z_{i}$ is the measuring instrument accuracy, and $z_{i}$ is the minimal magnitude of the measured output. Pressure and temperature are directly considered in file with accuracy of 0.01 bar and $0.1^{\circ} \mathrm{C}$, respectively. The maximum feasible errors in the case of pressure and temperature measurement are:

$$
\begin{aligned}
\frac{\partial T}{T} & =\sqrt{\left(\frac{\partial T_{\mathrm{PT} 100}}{T_{\min }}\right)^{2}+\left(\frac{\partial T_{\mathrm{log}}}{T_{\min }}\right)^{2}} \\
& =\sqrt{\left(\frac{0.5}{10}\right)^{2}+\left(\frac{0.1}{10}\right)^{2}}=0.05=5 \%, \\
\frac{\partial P}{P} & =\sqrt{\left(\frac{\partial P_{\mathrm{trans}}}{P_{\min }}\right)^{2}+\left(\frac{\partial P_{\mathrm{log}}}{P_{\min }}\right)^{2}} \\
& =\sqrt{\left(\frac{0.01}{1.11}\right)^{2}+\left(\frac{0.01}{1.11}\right)^{2}}=0.01=1 \% .
\end{aligned}
$$

\section{CFD equations}

The gas in the numerical model can be assumed as a compressible, fully turbulent, and three-dimensional flow. The fully turbulent nature of the air stream is considered by the $k-\varepsilon$ turbulence viscous model. The computational fluid dynamics code employs the FVM (Finite Volume Method) approach and uses the SIMPLE (Semi-Implicit Method for Pressure-Linked Equations) velocity-pressure coupling algorithm. Also, the second-order upwind discretization is used. 


\subsection{Continuity equation}

In computational fluid dynamics/CFD approach, the expression of law of mass conservation is the continuity equation; it can be written as (in vector form):

$$
\frac{\partial \rho}{\partial t}+\Delta(\rho \vec{v})=0
$$

where, $\rho$ represents density, $\vec{v}$ is velocity of fluid streams, and $t$ is time.

Eq. (8) is the mass conservation law and is valid for compressible streams as well as incompressible fields. For steady-state simulation with no mass addition within the domain, the appropriate form of the conservation law is:

$$
\Delta(\rho \vec{v})=0
$$

\subsection{Momentum conservation equation}

The second law of Newton explains that the rate of momentum change of a particle in fluid field equals the sum of flow forces (two types including body and surface forces) on the particle in fluid. The $x, y$, and $z$-momentum increase rates per unit volume of a flow particle are written as:

$$
\rho \frac{D v_{x}}{D t}, \quad \rho \frac{D v_{y}}{D t}, \quad \text { and } \quad \rho \frac{D v_{z}}{D t} .
$$

The body forces are:

$$
B_{F x}, \quad B_{F y}, \quad \text { and } \quad B_{F z} .
$$

The $x$-direction momentum equation is found by adjusting the $x$-momentum change rate of the flow particle (Eq. (10)) equal to the total force on the flow element in the $x$ direction:

$$
\rho \frac{D v_{x}}{D t}+\frac{\partial P}{\partial x}-\frac{\partial \tau_{x x}}{\partial x}-\frac{\partial \tau_{y x}}{\partial y}-\frac{\partial \tau_{z x}}{\partial z}-B_{F x}=0
$$

in the $y$ direction:

$$
\rho \frac{D v_{y}}{D t}+\frac{\partial P}{\partial y}-\frac{\partial \tau_{x y}}{\partial x}-\frac{\partial \tau_{y y}}{\partial y}-\frac{\partial \tau_{z y}}{\partial z}-B_{F y}=0
$$

and in the $z$ direction:

$$
\rho \frac{D v_{z}}{D t}+\frac{\partial P}{\partial z}-\frac{\partial \tau_{x z}}{\partial x}-\frac{\partial \tau_{y z}}{\partial y}-\frac{\partial \tau_{z z}}{\partial z}-B_{F z}=0 .
$$

\subsection{Energy equation}

The equation of energy comes from the first law of thermodynamics, which explains that the rate of energy change of a particle in fluid is equal to the heat addition rate to the particle in fluid plus the work rate done on the particle in fluid. The rate of energy increase in a flow stream or fluid per unit volume is given by:

$$
\rho \frac{D E}{D T}
$$

The governing equations can usually be presented as:

$$
\begin{gathered}
\frac{\partial}{\partial t}(\rho E)-\nabla\left(k_{\mathrm{eff}} \nabla T-\sum_{i} h_{i} \vec{J}_{i}+\left(\overline{\overline{\tau_{\mathrm{eff}} \times \vec{u}}}\right)\right) \\
-S_{c}+(\vec{v}(\rho E+P))=0
\end{gathered}
$$

and:

$$
E=h+\frac{v^{2}}{2}-\frac{P}{\rho} .
$$

In the mentioned equation, the effective conductivity is presented as $k_{\text {eff }}$, the diffusion flux $i$ is $\vec{J}_{i}$, and $S_{c}$ is the chemical reaction heat. We assumed that the fluid or air was an ideal gas; thus, the compressible effect is estimated by:

$$
p=\rho R T \text {. }
$$

\subsection{Standard $k-\varepsilon$ model equation}

The standard $k-\varepsilon$ turbulence computing is a semiempirical modeling on the basis of computational transport equations for the dissipation rate $(\varepsilon)$ and flow turbulent kinetic energy $(k)$. In the explanation of $k-\varepsilon$ turbulence computing, the assumptions are that first, the flow is fully turbulent and second, the molecular viscosity effects are neglected. The transport equations are:

$$
\begin{gathered}
\frac{\partial}{\partial t}(\rho k)-\frac{\partial}{\partial x_{j}}\left[\left(\mu+\frac{\mu_{t}}{\sigma_{k}}\right) \frac{\partial k}{\partial x_{j}}\right]+\frac{\partial}{\partial x_{i}}\left(\rho k u_{i}\right) \\
-G_{k}-G_{k b}+\rho \varepsilon+Y_{M}-S_{k}=0,
\end{gathered}
$$

and:

$$
\begin{aligned}
\frac{\partial}{\partial t}(\rho \varepsilon) & -\frac{\partial}{\partial x_{i}}\left[\left(\mu+\frac{\mu_{t}}{\sigma_{\varepsilon}}\right) \frac{\partial \varepsilon}{\partial x_{i}}\right]+\frac{\partial}{\partial x_{i}}\left(\rho \varepsilon u_{i}\right) \\
& -C_{1 \varepsilon} \frac{\varepsilon}{k}\left(G_{k}-G_{b} C_{3 \varepsilon}\right)+C_{2 \varepsilon} \rho \frac{\varepsilon^{2}}{k}-S_{E}=0,
\end{aligned}
$$

where, $G_{k}$ shows the turbulent kinetic energy generation by the mean velocity variations and $G_{b}$ represents the turbulence kinetic energy generation by buoyancy. In fact, the constants in these equations are presented by $C_{1 \varepsilon}, C_{2 \varepsilon}$, and $C_{3 \varepsilon}$. Also, $\sigma_{\varepsilon}$ and $\sigma_{k}$ represent turbulent Prandtl numbers regarding $\varepsilon$ and $k$.

\section{CFD simulation and mesh independence test}

In this investigation, ANSYS FLUENT software was used to predict the heat and mass transfer procedure in the convergent vortex tube. In order to simplify the computations, the following assumptions were considered: 
Table 2. Under-relaxation factors applied for predictions.

\begin{tabular}{lccccccc}
\hline Under-relaxation factor & Default value & Step 1 & Step 2 & Step 3 & Step 4 & Step 5 & Step 6 \\
\hline Pressure & 0.3 & 0.1 & 0.2 & 0.3 & 0.3 & 0.3 & 0.3 \\
Density & 1 & 0.1 & 0.4 & 0.6 & 0.8 & 0.9 & 1 \\
Body force & 1 & 0.1 & 0.4 & 0.6 & 0.8 & 0.9 & 1 \\
Moment um & 0.7 & 0.1 & 0.3 & 0.5 & 0.6 & 0.7 & 0.7 \\
Turbulent kinetic energy & 0.8 & 0.1 & 0.3 & 0.5 & 0.7 & 0.8 & 0.8 \\
Turbulent dissipation rate & 0.8 & 0.1 & 0.3 & 0.5 & 0.7 & 0.8 & 0.8 \\
Turbulent viscosity & 1 & 0.1 & 0.4 & 0.6 & 0.8 & 0.9 & 1 \\
Energy & 1 & 0.1 & 0.4 & 0.6 & 0.8 & 0.9 & 1 \\
\hline
\end{tabular}

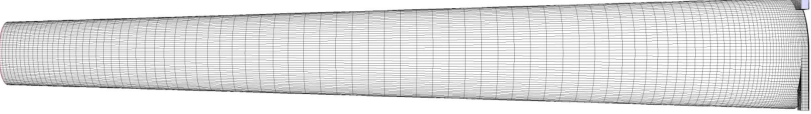

(a)

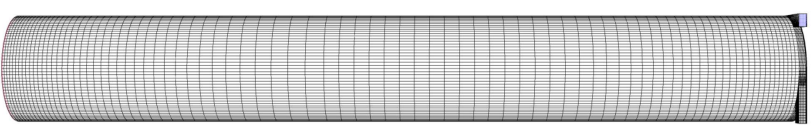

(b)

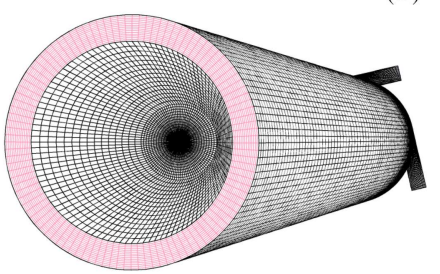

(c)

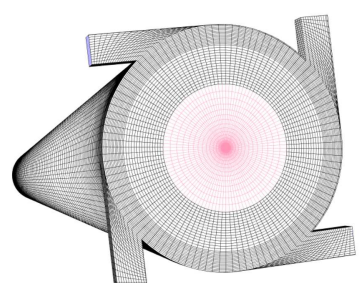

(d)
Figure 4. Schematic plot of boundary conditions.

1. The outer walls were considered as insulated surfaces;

2. The air flow in each part of the vortex tube was fully turbulent;

3. The fluid flow was in steady state and compressible.

The simulation or computation is on the basis of the pre-set operation geometries as shown in Table 1. A computational model and the real model are geometrically the same if and only if all geometrical dimensions in all three dimensions have the same values. The three-dimensional mesh grids have been shown in Figure 4. The convergent hot tube angle of the main tube and the diameter of cold orifice are the major geometrical parameters which affect the cooling ability or heating effectiveness. Further experimental/computational results are taken by changing one of these factors when other geometrical factors are maintained constant. The grid for the numerical domain was created applying Gambit. Different grid numbers have been employed to check the mesh independency. Mesh independence test is important to ascertain validity, stability, and accuracy of the computational results. This section demonstrates the mesh independence test of the vortex tube in detail.
Five tests are performed for mesh numbers of 740,527 , $980,100,1,285,895,1,861,432$, and 2,951,940. The cold temperature difference $\left(\Delta T_{c}\right)$ regarding this models are $15.48,17.82,20.19,20.52$, and $20.97 \mathrm{~K}$, respectively (For $\beta=0, L_{\text {convergent }}=185 \mathrm{~mm}$ and $D_{\text {cold }}=8 \mathrm{~mm}$ ). The relative error of $\Delta T_{c}$ between case 3 and case 4 is $1.6 \%$ and the mesh number of $1,285,895$ is finally chosen considering the validity, stability, and accuracy of the numerical data and the computer resource. The range of values for the under-relaxation factors is denoted in Table 2 step by step. This is to improve stability. In fact, the low under-relaxation factors help to provide stability for the solution, especially for the high-speed flows (the flow field inside the vortex tube). Setting low values for URFs means that it will take longer to reach the final solution. Thus, in this way, the solution is more reliable and accurate.

\section{Boundary conditions}

The numerical domain is composed of three boundary surfaces: inlet, cold outlet, and hot outlet surfaces as in the schematic in Figure 5. We start by considering the boundary conditions within the wall of the vortex tube. To produce the uniform inlet flow and velocity pattern and avoid velocity with a circular pattern, the numerical domain is extended along the inlet by 2 times the nozzle length at the position of the injector. At the injector or inlet surface, the air enters the numerical

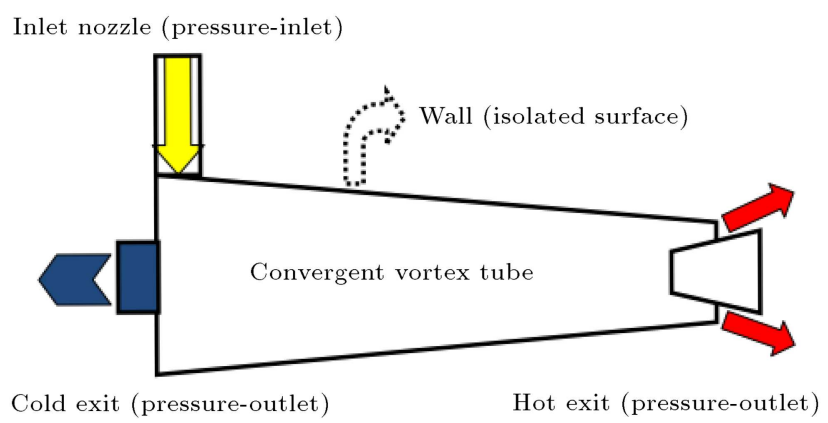

Figure 5. Schematic demonstration of mesh domain: (a) Convergent VT; (b) straight VT; (c) control valve position; and (d) nozzle injectors position. 
Table 3. Boundary conditions.

\begin{tabular}{ll}
\hline Inlet injectors & $\begin{array}{l}\text { Pressure inlet, } \\
\text { Temperature } 293 \mathrm{~K}\end{array}$ \\
& Pressure-outlet, \\
& Experimental pressure, \\
Cold outlet & Initial Mach number 0.3, \\
& $z$ direction velocity, \\
& Initial temperature 290 K \\
& \\
& Pressure-outlet, \\
& Initial Mach number 0.4, \\
Hot outlet & $z$ direction velocity, \\
& Initial temperature $320 \mathrm{~K}$ \\
\hline
\end{tabular}

domain along the $y$ direction at the certain pressure $P_{\text {inlet }}$ and the inlet temperature $T_{\text {inlet }}(293 \mathrm{~K})$, and the cold pressure component along the $z$ direction is set to be the experimental pressure value (cold experimental pressure). On the basis of the Fluent Manual offer, the turbulent intensity $K$ is $5 \%$. As we know, the air flow or fluid pattern plays a strong and important role in the cooling ability of vortex tube, and the geometrical factors of the convergent vortex tube have great influences on the cooling ability and heating efficiency. Thus, proper optimization is essential for geometrical parameters. The boundary conditions corresponding to the surfaces for the CFD model are summarized in Table 3 .

\section{Validation}

Apart from the mesh-independency analysis, we should verify and analyze the numerical accuracy of the computational model.

The numerical geometry parameters of the convergent vortex tube are the same with the ones denoted in the experimental tests. Emphasis is on the temperatures at the end sides (hot and cold) as these factors have a high level of importance for the efficiency comparison. All reported comparisons between the numerical results and the measured or laboratory data are presented in terms of the cold flow ratio. Following the comparison and validation processes recommended in previous studies $[7,8]$, the experimental comparison/validation of the numerical method was done under different values of $\beta$ in the mentioned operating condition, by comparing the cold and the hot temperature drops at the exit sides (cold and hot), as shown in Figure 6 . In fact, changing the pressure at the hot side caused the pressure at the cold side to change as the pressure difference corresponded to the additional fluid stream through the cold end side. According to the results, the 3D CFD model usually over-predicted (contrary to the predicted temperature drops) the pressure at the hot side required for a specific cold flow ratio; however, the general treatment agrees very well with experimental results. The temperature at the injectors in the model was fixed, as a constant value, at $293 \mathrm{~K}$, which was equal to the taken temperature at the inlet line to the air separator. To use the air separator/VT with the cold flow ratios lower than 0.35 , it was important to rise the pressure at the cold side, which was done applying the valves on the rotameters at the cold line; pressure rise of air at the cold side results in a corresponding pressure rise of flow at the hot end. The maximum and the average discrepancies between the simulated/predicted cold temperature drop and the experimental values are $4.31 \%$ and $2.23 \%$, respectively, and the maximum and the average discrepancies between the simulated/predicted hot temperature drop and the experimental values are $5.82 \%$ and $2.52 \%$, respectively. The full and exact agreement between the simulated and the experimental data proves that the present computational simulation and method are reliable to analyze and predict the heat separation and the flow treatments. It is very important that in the computational modeling, the pressure of cold side/exhaust was fixed at the measured experimental pressure and the pressure at the hot side was iteratively adjusted until the experimental cold flow ratio was reached. Figure 6 shows the thermophysical characteristic variations for $\beta=0^{\circ}, 1^{\circ}, 3^{\circ}, 5^{\circ}, 7^{\circ}$, and $9^{\circ}$, $L_{\text {convergent }}=185 \mathrm{~mm}$, and $D_{\text {cold }}=8 \mathrm{~mm}$. Tables 4 and 5 denote the disagreement between the predicted and the laboratory data for the cold and hot measured temperatures data at the optimal cold flow ratio.

\section{Results and discussion}

In these activities, the experiments and the simulations focused on the effects of main or hot tube convergent angle and cold orifice diameter on the cooling ability of convergent vortex tube. The optimum values have been selected for all series and the effect of hot tube angle on the cooling value is studied.

Table 4. The disagreement between laboratory and measured results for cold thermal drop at optimal cold flow ratio.

\begin{tabular}{cccc}
\hline $\begin{array}{c}\text { Angle } \\
(\mathbf{d e g})\end{array}$ & $\begin{array}{c}\boldsymbol{\Delta} \boldsymbol{T}_{\mathbf{c}} \operatorname{Exp} \\
(\mathbf{K})\end{array}$ & $\begin{array}{c}\Delta \boldsymbol{T}_{\mathbf{c}} \text { Num } \\
(\mathbf{K})\end{array}$ & $\begin{array}{c}\text { Disagreement } \\
(\boldsymbol{\%})\end{array}$ \\
\hline$\beta=0$ & 21.1 & 20.19 & 4.31 \\
$\beta=1$ & 22.54 & 22.85 & 1.37 \\
$\beta=3$ & 25.07 & 24.84 & 0.91 \\
$\beta=5$ & 27.86 & 26.85 & 3.62 \\
$\beta=7$ & 26.25 & 26.67 & 1.6 \\
$\beta=9$ & 18.32 & 18.03 & 1.58 \\
\hline
\end{tabular}



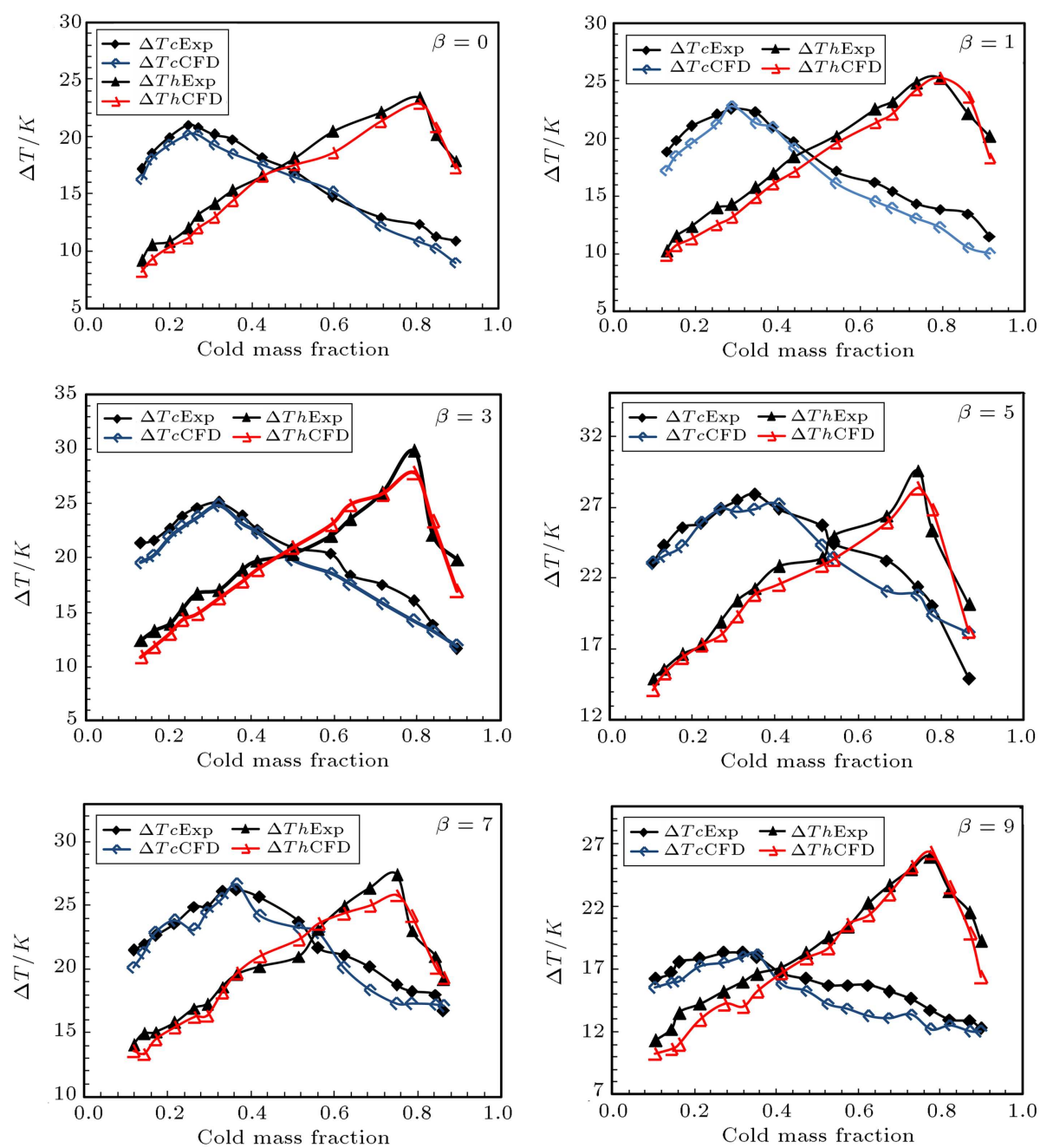

Figure 6. Model validation for different convergent hot tubes.

Table 5. The disagreement between laboratory and measured results for hot thermal drop at optimal cold flow ratio.

\begin{tabular}{cccc}
\hline $\begin{array}{c}\text { Angle } \\
(\mathbf{d e g})\end{array}$ & $\begin{array}{c}\boldsymbol{\Delta} \boldsymbol{T}_{\boldsymbol{h}} \text { Exp } \\
(\mathbf{K})\end{array}$ & $\begin{array}{c}\boldsymbol{\Delta} \boldsymbol{T}_{\boldsymbol{h}} \text { Num } \\
(\mathbf{K})\end{array}$ & $\begin{array}{c}\text { Disagreement } \\
(\boldsymbol{\%})\end{array}$ \\
\hline$\beta=0$ & 23.42 & 22.91 & 2.17 \\
$\beta=1$ & 25.19 & 25.24 & 0.19 \\
$\beta=3$ & 28.25 & 27.84 & 1.45 \\
$\beta=5$ & 29.56 & 28.31 & 4.22 \\
$\beta=7$ & 27.45 & 25.85 & 5.82 \\
$\beta=9$ & 25.98 & 26.32 & 1.3 \\
\hline
\end{tabular}

\subsection{Effect of convergent angle}

In this section, the effects of main tube angle $(\beta)$ are tested experimentally and computationally on the cooling capability and heating effectiveness. Six hot/main tubes are used in these setups with the main/hot tube angles of $0,1,3,5,7$, and $9 \mathrm{deg}$. It should be emphasized that the effect of angle of convergent hot tube has not been analyzed in the previous scientific

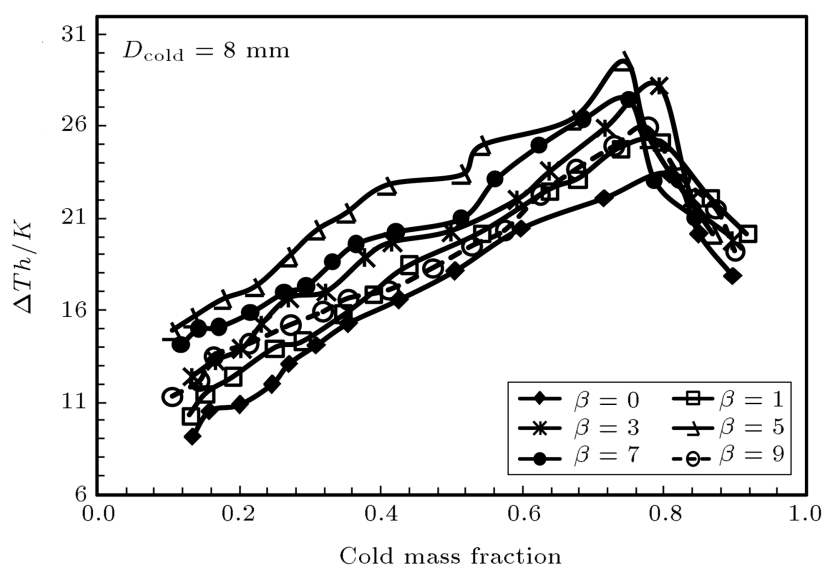

Figure 7. Effect of convergent hot tube angle on hot temperature drop.

research. Main tube is the main conduit and the flow is separated through this part. Thus, the shape or the change of hot tube angle influences the flow treatment and heat manner inside the air separator and the cooling ability as a consequence. Figures 7 and 8 


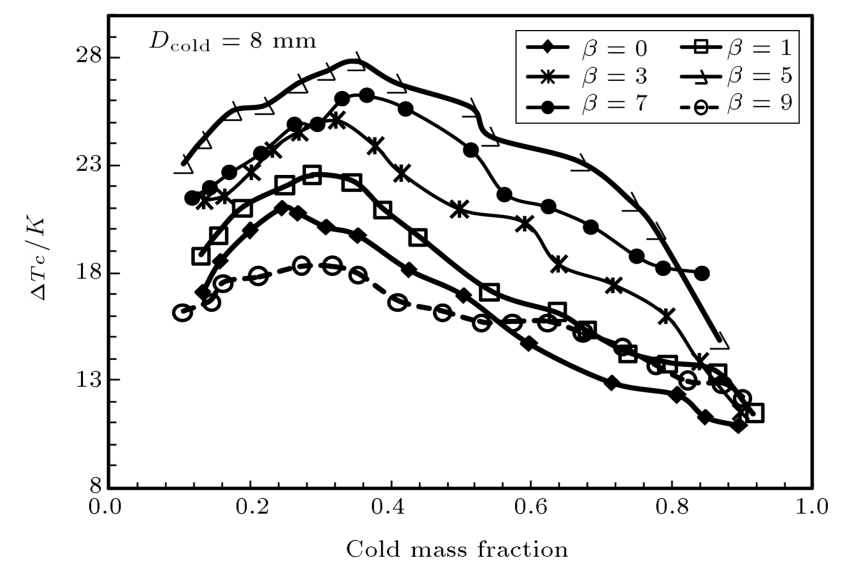

Figure 8. Effect of convergent hot tube angle on cold temperature drop.

demonstrate the thermal difference variation against the cold ratio variance. As shown in Figures 7 and 8, for each main tube, hot temperature drop improved continuously over the cold fraction period of 0.15 to 0.8 ; then, it decreased over the range of 0.8 to 0.9 . Also, the cold thermal drop denoted a similar trend. The cold thermal drop ascended over the cold fraction period of 0.15 to 0.25 and then descended. The cold drop reaches the maximum value at $\alpha=0.23-0.35$ and then drops to the minimum value at $\alpha=0.82-0.9$. It can be understood that the hot tube angle has a significant influence on the temperature drops. Attention to the main angle effects denotes that the highest thermal ability could be achieved at $\beta=5 \mathrm{deg}$. The thermal graphs (cold and hot temperatures) prove that the cooling and heating abilities rise using the convergent hot tube except for at $\beta=9 \mathrm{deg}$. The results denote that the cooling ability or effectiveness descends using the hot tube angle $\beta=9 \mathrm{deg}$. In other words, the convergent VT can obtain a high cooling and heating effectiveness when the convergent angle of main tube is equal to or less than $7 \mathrm{deg}$. Figures 7 and 8 emphasize that both heating effectiveness and cooling effectiveness reach a maximum value when the hot tube angle is around 5 deg.

The improvement (compared to $\beta=0$ or the straight vortex tube) of heating and cooling abilities is explained in Table 6 . Table 6 shows the fact that applying the convergent VTs and optimization of hot tube convergent angle elevate the cooling and heating effectiveness to around 32.03 and $26.21 \%$, respectively. The isentropic cooling efficiency of the convergent VT

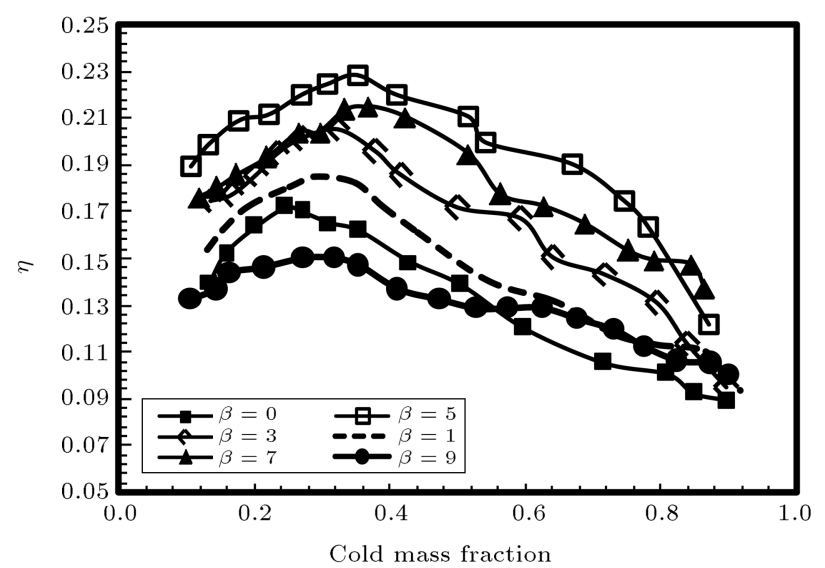

Figure 9. Effect of convergent hot tube angle on convergent VT efficiency.

is calculated on basis of Eq. (4) as illustrated in Figure 9. Because the isentropic cooling efficiency is a function of cold thermal drop, it has a similar variation with that of the cold temperature drop. Actually, in Eq. (4), the cold thermal drop $\left(\Delta T_{c}\right)$ is multiplied by a constant value. By raising convergent hot tube angle from 0 to $9 \mathrm{deg}$, the location of the best cold flow ratio on the cold flow ratio axis is between $\alpha=0.23$ and 0.35 (the best efficiency is taken for the cold mass fraction changing between 0.23 and 0.35). The angle of $5 \mathrm{deg}$ suggests the best cooling efficiency among six hot tubes. This convergent main tube offers the highest cooling efficiency among other main tubes at the flow ratio of 0.35 with the cooling efficiency of $22.9 \%$. For convergent hot tube angles smaller or greater than $5 \mathrm{deg}$, the efficiency decreases. The cold flow ratio that corresponds to the maximum cooling ability or efficiency (or cold temperature drop) is named optimal cold flow ratio in this research. The hot tube angle affects not only the efficiency value, but also the position of the occurrence of optimum cold flow ratio. Besides the cooling efficiency, the optimum cold flow ratio is also affected by the convergent hot tube angle. Figure 10 shows the temperature flow fields inside the air separator for $\beta=5$ (optimized) and 0 deg (non-optimized), respectively. In order to more explain the base of the optimization, a nonoptimized air separator or $\beta=0$ case is shown in Figure 10; the total temperature contours explain the inappropriate flow structures caused by the nonoptimized hot tube. As a conclusion, the hot flow field is confined in the middle region of the hot tube.

Table 6. $\Delta T$ improvement of convergent VT with optimum angle compared to $\beta=0$ or straight vortex tube (basic model).

\begin{tabular}{lccccc}
\hline & $\boldsymbol{\beta}=\mathbf{1}$ & $\boldsymbol{\beta}=\mathbf{3}$ & $\boldsymbol{\beta}=\mathbf{5}$ & $\boldsymbol{\beta}=\mathbf{7}$ & $\boldsymbol{\beta}=\mathbf{9}$ \\
\hline $\boldsymbol{\Delta} \boldsymbol{T}_{\boldsymbol{c}}$ improvement (\%) & 6.82 & 18.81 & 32.03 & 24.4 & -13.17 \\
$\boldsymbol{\Delta} \boldsymbol{T}_{\boldsymbol{h}}$ improvement (\%) & 7.55 & 20.62 & 26.21 & 17.21 & 10.93 \\
\hline
\end{tabular}




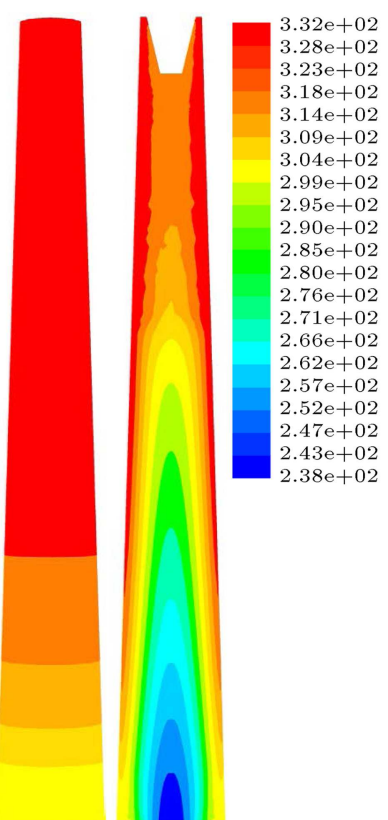

(a) Convergent VT

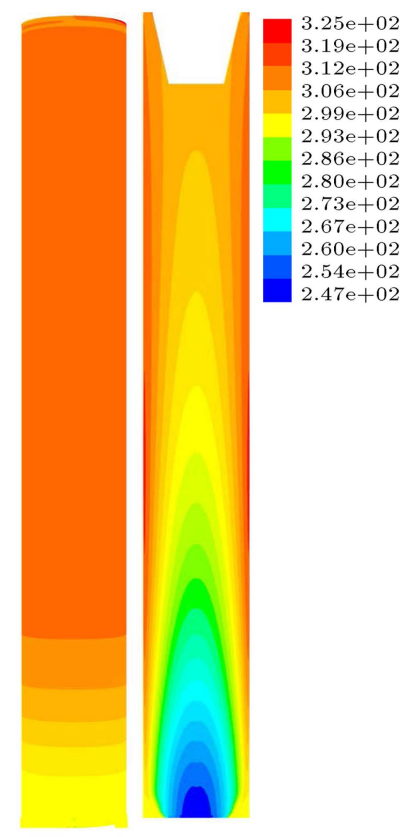

(b) Straight VT
Figure 10. Temperature fields for convergent VTs and straight one in comparison form.

The two streams are poorly separated and the vortex tube is penalized. The maximum hot temperature occurs in the middle region and is equal to $325 \mathrm{~K}$, while the maximum temperature should occur at the hot end side. In optimized convergent vortex tube (Figure 10(a)), the hot air with maximum temperature is conducted in the hot end side and the maximum temperature is equal to $332 \mathrm{~K}$. Thus, the base of thermal separation in the optimized convergent vortex tube is so efficient compared to the straight one and it is clear from this contour that the performance improves with increasing the degree of convergent hot tube up to $5 \mathrm{deg}$. The velocity distribution and the total pressure contours are shown in Figures 11 and 12, respectively. According to Figure 12, the convergent vortex tube (Figure 12(a)) has a greater magnitude of pressure drop across the working tube than that of the straight VT (Figure 12(b)). As seen in Figure 12, the convergent VT pressure drop is $732.3 \mathrm{kPa}$ across the main tube, while this value is $697.9 \mathrm{kPa}$ for the straight VT. This value of pressure drop shows an appropriate energy and flow separation procedure in the convergent VT.

\subsection{Cold orifice diameter effect}

Five cold orifices with various diameters are used in this part of analysis with the cold orifice diameters of $7.5,8,8.5,9$, and $9.5 \mathrm{~mm}$. It should be emphasized that the effect of diameter of cold orifice of convergent vortex tube has not been analyzed numerically and experimentally in the previous scientific works (Saidi and Valipour [3] analyzed the cold orifice diameter for the straight vortex tubes, but not for the convergent

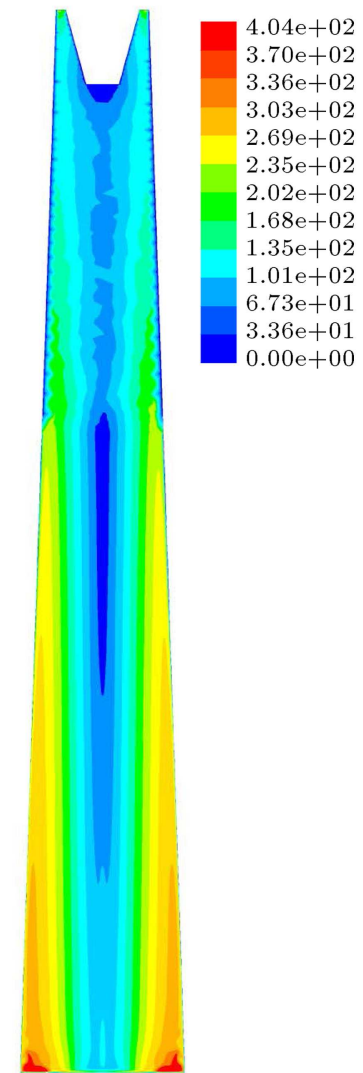

(a) Convergent VT

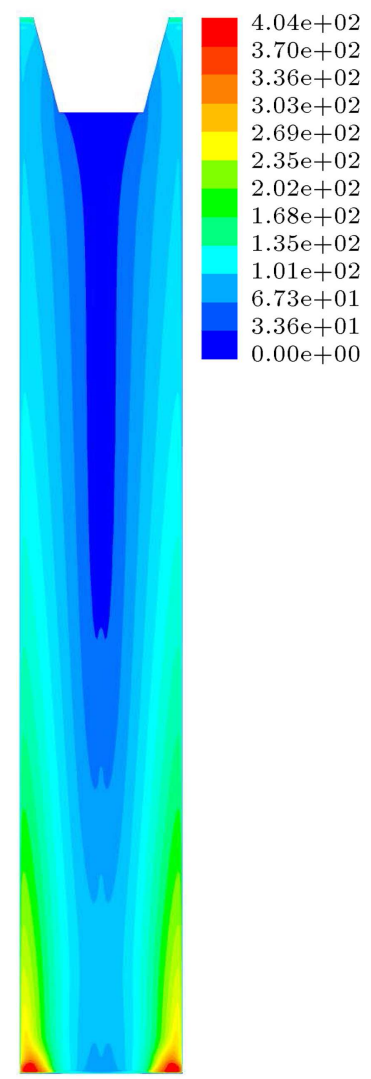

(b) Straight VT
Figure 11. Velocity fields for convergent VTs and straight one in comparison form.

vortex tubes). The cooling and heating capabilities of a VT air separator are influenced by both the mentioned factors, i.e. the convergent main tube angle and the diameter of cold orifice. The thermophysical influence of the cold orifice diameter was identified using the mentioned diameter $\left(D_{\text {cold }}\right)$. The variations of the trends of hot and cold thermal drops $\left(\Delta T_{h}\right.$ and $\Delta T_{c}$ ) against the cold flow ratio are sketched in Figures 13 and 14, respectively. The variations of temperature drops have a similar trend with those of the previous figures discussed in the previous section. Figures 13 and 14 concentrate on the efficacy of the cold orifice diameter $\left(D_{\text {Cold }}\right)$ in the cooling capability. The laboratory results were taken by shifting the cold orifice diameter between 7.5 and $9.5 \mathrm{~mm}$, while holding other parameters unchanged $(\beta=5 \mathrm{deg})$ under the set conditions. The rise in the horizontal axis values (cold flow ratio) in a range of 0.15 to 0.8 creates a higher hot temperature drop (Figure 13). According to Figures 13 and 14 , the results display that the cooling drop and the heating effectiveness rise with increasing cold orifice diameter up to $9 \mathrm{~mm}$. This may be due to the fact that longer (up to $9 \mathrm{~mm}$ ) cold orifice diameter leads to a rise in the swirl velocity drop between the chamber and the hot side. Therefore, the thermal separation process can be improved in the channel. To gain a high cooling 


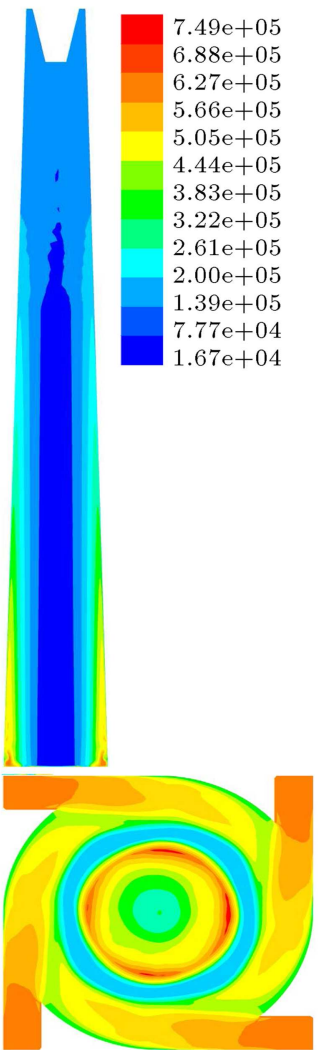

(a) Convergent VT

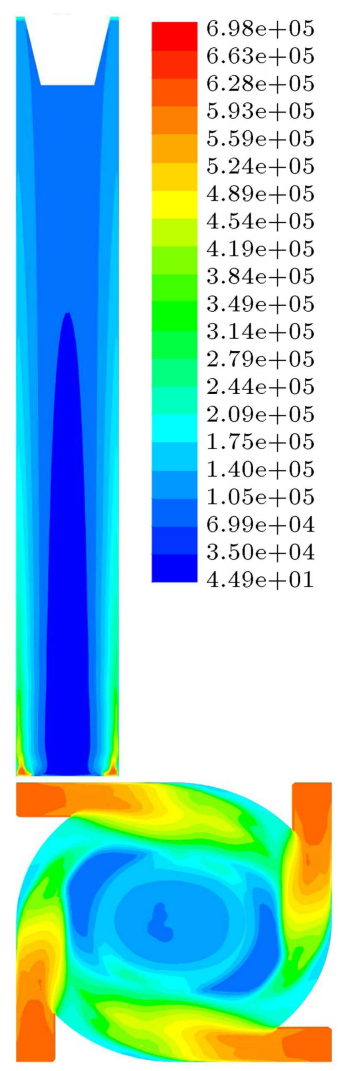

(b) Straight VT
Figure 12. Pressure fields for convergent VTs and straight one in comparison form $(\mathrm{Pa})$.

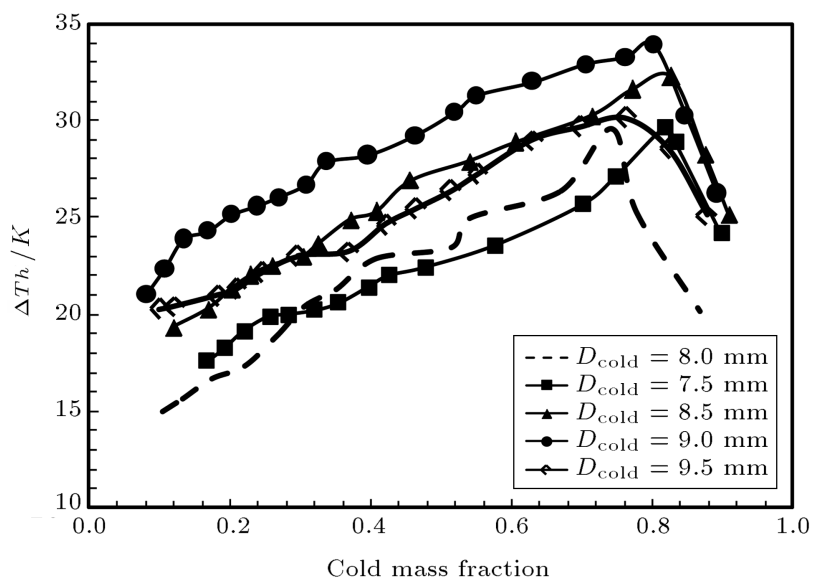

Figure 13. Effect of cold orifice diameter on hot temperature drop.

ability and heating effectiveness, it is offered that the cold orifice diameter should be at least $9 \mathrm{~mm}$. For these air separators in the setup, the product $D_{\text {cold }}$ was changed from $7.5 \mathrm{~mm}$ to $9 \mathrm{~mm}$ and from $9 \mathrm{~mm}$ to $9.5 \mathrm{~mm}$, while $\beta$ was considered to be $5 \mathrm{deg}$. All other condition factors were considered fixed at the preset operational condition, i.e. 4 injectors at chamber, $293 \mathrm{~K}$ of air temperature at the injectors, and air as the system fluid. Figures 13 and 14 denoted that both

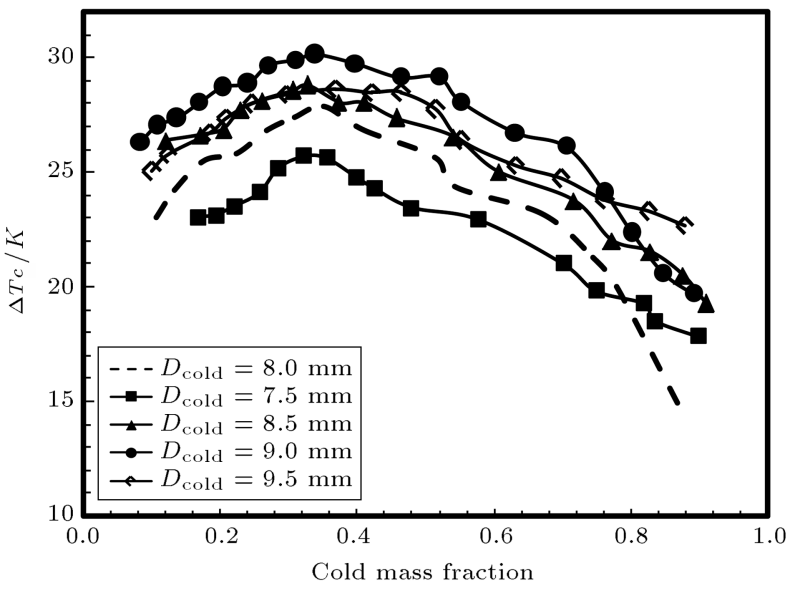

Figure 14. Effect of cold orifice diameter on cold temperature drop.

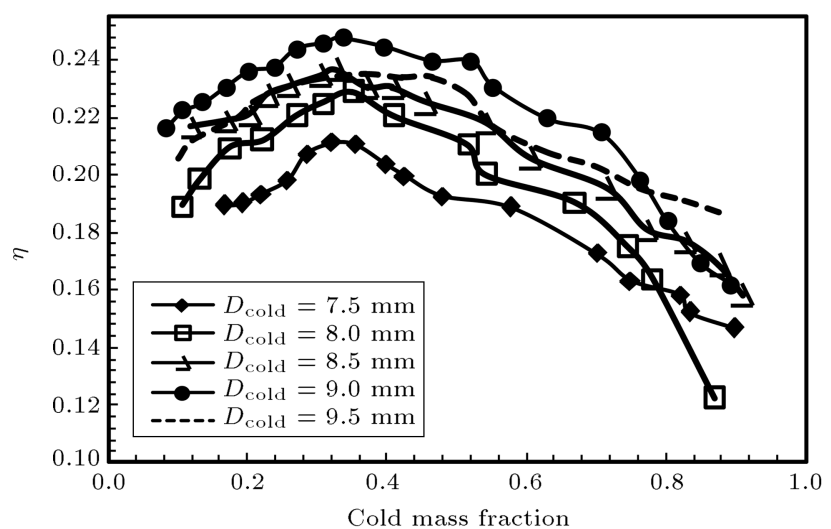

Figure 15. Effect of cold orifice diameter on convergent VT efficiency.

cooling capability and heating effectiveness reach the highest magnitudes when $D_{\text {cold }}$ is around $9 \mathrm{~mm}$. The cold orifice diameters lower or higher than $9 \mathrm{~mm}$ lead to upsets affecting the thermal or the fluid separation processes of convergent vortex tube. This means that a drop or increase of the cold orifice diameter from the optimum cold orifice diameter $(9 \mathrm{~mm})$ leads to a sharp drop in cold and hot thermal drops.

The improvement of heating and cooling abilities is explained in Table 7 (compared to $\beta=0$ or the straight vortex tube). Two previous tables prove the fact that applying the convergent VTs and the optimization of geometrical factors (cold orifice diameter and angle) improve the cooling and heating capabilities by around 42.89 and $44.74 \%$, respectively. Figure 15 displays the isentropic cooling efficiency for all convergent vortex tubes with different cold orifices. Among all orifices, the highest cooling efficiency is of the orifice with the diameter of $9 \mathrm{~mm}$. For this orifice, the efficiency reaches $24.7 \%$ at the cold flow ratio of 0.33. The offered (optimized) cooling air separator was capable of decreasing and rising the air temperatures at the cold and hot sides up to $9.05 \mathrm{~K}(42.89 \%)$ 
Table 7. $\Delta T$ improvement of convergent VT with optimum diameter of cold orifice and convergent angle compared to $\beta=0$ or straight one (basic model).

\begin{tabular}{lccccc}
\hline & $\boldsymbol{D}=\mathbf{7 . 5} \mathbf{~ m m}$ & $\boldsymbol{D}=\mathbf{8 . 0} \mathbf{~ m m}$ & $\boldsymbol{D}=\mathbf{8 . 5} \mathbf{~ m m}$ & $\boldsymbol{D}=\mathbf{9 . 0} \mathbf{~ m m}$ & $\boldsymbol{D}=\mathbf{9 . 5} \mathbf{~ m m}$ \\
\hline $\boldsymbol{\Delta} \boldsymbol{T}_{\boldsymbol{c}}$ improvement (\%) & 21.89 & 32.03 & 36.58 & 42.89 & 35.78 \\
$\boldsymbol{\Delta} \boldsymbol{T}_{\boldsymbol{h}}$ improvement (\%) & 26.6 & 26.21 & 37.7 & 44.74 & 28.65 \\
\hline
\end{tabular}

Table 8. The disagreement between laboratory and measured results for cold thermal drop at optimal cold flow ratio.

\begin{tabular}{|c|c|c|c|}
\hline $\begin{array}{c}\text { Cold } \\
\text { diameter }\end{array}$ & $\begin{array}{c}\Delta T_{c} \operatorname{Exp} \\
\quad(\mathrm{K})\end{array}$ & $\begin{array}{c}\Delta T_{c} \text { Num } \\
\quad(\mathrm{K})\end{array}$ & $\begin{array}{c}\text { Disagreement } \\
(\%)\end{array}$ \\
\hline$D_{\text {Cold }}=7.5 \mathrm{~mm}$ & 25.72 & 24.92 & 3.12 \\
\hline$D_{\text {Cold }}=8.0 \mathrm{~mm}$ & 27.86 & 26.85 & 3.62 \\
\hline$D_{\text {Cold }}=8.5 \mathrm{~mm}$ & 28.82 & 27.72 & 3.82 \\
\hline$D_{\text {Cold }}=9.0 \mathrm{~mm}$ & 30.15 & 28.89 & 4.17 \\
\hline$D_{\text {Cold }}=9.5 \mathrm{~mm}$ & 28.65 & 27.43 & 4.25 \\
\hline
\end{tabular}

Table 9. The disagreement between laboratory and measured results for hot thermal drop at optimal cold flow ratio.

\begin{tabular}{|c|c|c|c|}
\hline $\begin{array}{c}\text { Cold } \\
\text { diameter }\end{array}$ & $\begin{array}{c}\Delta T_{h} \operatorname{Exp} \\
\quad(\mathbf{K})\end{array}$ & $\begin{array}{l}\Delta T_{h} \text { Num } \\
\quad(\mathbf{K})\end{array}$ & $\begin{array}{c}\text { Disagreement } \\
(\%)\end{array}$ \\
\hline$D_{\text {Cold }}=7.5 \mathrm{~mm}$ & 29.65 & 29.02 & 2.12 \\
\hline$D_{\text {Cold }}=8.0 \mathrm{~mm}$ & 29.56 & 28.31 & 4.22 \\
\hline$D_{\text {Cold }}=8.5 \mathrm{~mm}$ & 32.25 & 30.83 & 4.40 \\
\hline$D_{\text {Cold }}=9.0 \mathrm{~mm}$ & 33.9 & 32.59 & 3.86 \\
\hline$D_{\text {Cold }}=9.5 \mathrm{~mm}$ & 30.13 & 29.41 & 2.38 \\
\hline
\end{tabular}

and $10.48 \mathrm{~K}(44.74 \%)$. The same CFD confirmation technique, which agrees well with our laboratory model in Section 8.1, is also successfully applied in this part. We present some brief comparison here. The average of dissimilarities and the maximum disagreement between the calculated $\Delta T_{c}$ and the laboratory data are $3.8 \%$ and $4.25 \%$, respectively, and the average of dissimilarities and the maximum disagreement between the calculated $\Delta T_{h}$ and the laboratory data are $3.39 \%$ and $4.40 \%$, respectively. The good coordination between the calculated and the laboratory outcomes proves that the offered numerical model and the computational way are dependable to decide on and predict the flow manner in the convergent VTs. Tables 8 and 9 denote the disagreement between the predicted and the laboratory data for the cold and hot measured data at the optimal cold flow ratio.

\section{Conclusions}

The cooling capability and the heating effectiveness of a convergent air separator vortex tube have been evaluated. In fact, the simplified convergent system used for cooling or heating environments or tools has been sketched and its output efficiencies in terms of thermal performances at two separate stages (optimization of convergent hot tube angle and cold orifice diameter) are evaluated (experimentally and computationally). Six hot/main tubes are used in these setups with the main/hot tube angles of $0,1,3,5,7$, and $9 \mathrm{deg}$. It can be understood that the hot tube angle has a significant influence on the temperature drops. Attention to main angle effects denotes that the highest thermal ability could be achieved at $\beta=5 \mathrm{deg}$. The laboratory setup results show that applying the convergent VTs and optimization of hot tube convergent angle elevate the cooling effectiveness and heating effectiveness by around 32.03 and $26.21 \%$, respectively. This convergent main tube offers the highest cooling efficiency among other main tubes at the flow ratio of 0.35 with the cooling efficiency of $22.9 \%$. For convergent hot tube angles smaller or greater than $5 \mathrm{deg}$, the efficiency decreases. Five orifices with various diameters are used in this part of analysis with the cold orifice diameters of $7.5,8,8.5,9$, and $9.5 \mathrm{~mm}$. The experiments denote that both cooling capability and heating effectiveness reach the highest magnitudes when $D_{\text {cold }}$ is around $9 \mathrm{~mm}$. The cold orifice diameters lower or higher than $9 \mathrm{~mm}$ lead to upsets affecting the thermal or the fluid separation processes of convergent vortex tube. This means that a drop or increase of the cold orifice diameter from the optimum cold orifice diameter $(9 \mathrm{~mm})$ leads to a sharp drop in the cold and hot thermal drops. After these two stages, the offered (optimized) cooling air separator was capable of decreasing and rising the air temperatures at the cold and hot sides up to $9.05 \mathrm{~K}$ $(42.89 \%)$ and $10.48 \mathrm{~K}(44.74 \%)$, respectively. This work created and developed a computational model to evaluate and predict the effect of key factors on the efficiency. The model was validated using the original experiment data and presented good accuracy with the disagreement within $5.82 \%$. The full and exact agreement between the simulated and experimental data proves that the present computational simulation and method are reliable to analyze and predict the heat separation in convergent VTs.

\section{Nomenclature}

$D \quad$ Diameter of vortex tube $(\mathrm{mm})$

$k \quad$ Turbulence kinetic energy $\left(\mathrm{m}^{2} \mathrm{~s}^{-2}\right)$

$L \quad$ Length of vortex tube (mm) 


$\begin{array}{ll}r & \text { Radial distance }(\mathrm{mm}) \\ T & \text { Temperature }(\mathrm{K}) \\ T_{i} & \text { Inlet gas temperature }(\mathrm{K}) \\ h & \text { Enthalpy }(\mathrm{kJ} / \mathrm{kg}) \\ Z & \text { Axial length }(\mathrm{mm}) \\ E & \text { Fluid energy }(\mathrm{kJ}) \\ D c & \text { Cold orifice diameter }(\mathrm{mm}) \\ \dot{m} & \text { Mass flow rate }\left(\mathrm{kg} \mathrm{s} \mathrm{s}^{-1}\right) \\ R^{*} & \text { Vortex-chamber radius } \\ S & \text { The width of a nozzle } \\ r^{*} & \text { Truncated cone radius }(\mathrm{mm}) \\ G & \text { Truncated ratio } \\ R_{W T} & \text { Working tube radius } \\ R_{C} & \text { Cold orifice radius } \\ v & \text { Velocity of flow } \\ P & \text { Pressure (kPa) } \\ B & \text { Body force (kN) } \\ S & \left.\text { Chemical reaction heat (kJ.mol }{ }^{-1}\right) \\ J & \text { Diffusion flux }\end{array}$

\section{Subscripts}

$\begin{array}{ll}\text { in } & \text { Inlet } \\ c & \text { Cold } \\ h & \text { Hot } \\ t & \text { Total } \\ x & x \text { direction } \\ y & y \text { direction } \\ z & z \text { direction }\end{array}$

\section{Greek symbols}

$\begin{array}{ll}\Delta T & \text { Temperature difference }(\mathrm{K}) \\ \alpha & \text { Cold mass fraction } \\ \beta & \text { Convergent angle } \\ \varepsilon & \text { Turbulence dissipation rate }\left(\mathrm{m}^{2} \mathrm{~s}^{-3}\right) \\ \rho & \text { Density }\left(\mathrm{kgm}^{-3}\right) \\ \sigma & \text { Stress }\left(\mathrm{Nm}^{-2}\right) \\ \mu & \text { Dynamic viscosity }\left(\mathrm{kgm}^{-1} \mathrm{~s}^{-1}\right) \\ \mu_{t} & \text { Turbulent viscosity }\left(\mathrm{kgm}^{-1} \mathrm{~s}^{-1}\right) \\ \tau & \text { Shear stress }(\mathrm{Nm}-2) \\ \tau_{i j} & \text { Stress tensor components }\end{array}$

\section{References}

1. Hilsch, R. "The use of expansion of gases in a centrifugal field as a cooling process", Rev. Sci. Instrum., 18(2), pp. 108-113 (1947).
2. Saidi, M.H. and Valipour, M.S. "Experimental modeling of vortex tube refrigerator", Applied Thermal Engineering, 23(15), pp. 1971-1980 (2003).

3. Xue, Y. and Arjomandi, M. "The effect of vortex angle on the efficiency of the Ranque-Hilsch vortex tube", Exp. Therm. Fluid. Sci., 33(1), pp. 54-57 (2008).

4. Dincer, K., Baskaya, S., Uysal, B.Z. and Ucgul, I. "Experimental investigation of the performance of a Ranque-Hilsch vortex tube with regard to a plug located at the hot outlet", Int. J. of Refrig., 32(1), pp. 87-94 (2009).

5. Aydın, O. and Baki, M. "An experimental study on the design parameters of a counter flow vortex tube", Energy, 31(14), pp. 2763-2772 (2006).

6. Rafiee, S.E. and Sadeghiazad, M.M. "Threedimensional and experimental investigation on the effect of cone length of throttle valve on thermal performance of a vortex tube using $k-\epsilon$ turbulence model", Applied Thermal Engineering, 66(1-2), pp. 65-74 (2014).

7. Rafiee, S.E., Sadeghiazad, M.M. and Mostafavinia, N. "Experimental and numerical investigation on effect of convergent angle and cold orifice diameter on thermal performance of convergent vortex tube", J. Thermal Sci. Eng. Appl., 7(4) (2015). DOI: 10.1115/1.4030639

8. Rafiee, S.E. and Rahimi, M. "Experimental study and three-dimensional (3D) Computational Fluid Dynamics (CFD) analysis on the effect of the convergence ratio, pressure inlet and number of nozzle intake on vortex tube performance-validation and CFD optimization", Energy, 63, pp. 195-204 (2013).

9. Rafiee, S.E. and Sadeghiazad, M.M. "Effect of conical. valve angle on cold-exit temperature of vortex tube", Journal of Thermophysics and Heat Transfer, 28, pp. 785-794 (2014). DOI: 10.2514/1.T4376

10. Rafiee, S.E., Ayenehpour, S. and Sadeghiazad, M.M. "A study on the optimization of the angle of curvature for a Ranque-Hilsch vortex tube, using both experimental and full Reynolds stress turbulence numerical modeling", Heat and Mass Transfer, 52(2), pp. 337350 (2015).

11. Berber, A., Dincer, K., Yılmaz, Y. and Ozen, D.N. "Rule-based Mamdani-type fuzzy modeling of heating and cooling performances of counter-flow Ranquee Hilsch vortex tubes with different geometric construction for steel", Energy, 51, pp. 297-304 (2013).

12. Rafiee, S.E. and Rahimi, M. "Three-dimensional simulation of fluid flow and energy separation inside a vortex tube", Journal of Thermophysics and Heat Transfer, 28, pp. 87-99 (2014). DOI: 10.2514/1.T4198

13. Rafiee, S.E., Rahimi, M. and Pourmahmoud, N. "Three-dimensional numerical investigation on a commercial vortex tube based on an experimental modelPart I: Optimization of the working tube radius", International Journal of Heat and Technology, 31(1), pp. $49-56$ (2013). 
14. Rafiee, S.E. and Sadeghiazad, M.M. "3D numerical analysis on the effect of rounding off edge radius on thermal separation inside a vortex tube", International Journal of Heat and Technology, 33(1), pp. 83-90 (2015).

15. Pourmahmoud, N., Rafiee, S.E., Rahimi, M. and Hasanzadeh, A. "Numerical energy separation analysis on the commercial Ranque-Hilsch vortex tube on basis of application of different gases", Scientia Iranica, 20(5), pp. 1528-1537 (2013).

16. Rahimi, M., Rafiee, S.E. and Pourmahmoud, N. "Numerical investigation of the effect of divergent hot tube on the energy separation in a vortex tube", International Journal of Heat and Technology, 31(2), pp. $17-26$ (2013).

17. Pourmahmoud, N., Rahimi, M., Rafiee, S.E. and Hasanzadeh, A. "A numerical simulation of the effect of inlet gas temperature on the energy separation in a vortex tube", Journal of Engineering Science and Technology, 9(1), pp. 81-96 (2014).

18. Pourmahmoud, N., Hasanzadeh, A., Rafiee, S.E. and Rahimi, M. "Three dimensional numerical investigation of effect of convergent nozzles on the energy separation in a vortex tube", International Journal of Heat and Technology, 30(2), pp. 133-140 (2012).

19. Rafiee, S.E. and Sadeghiazad, M.M. "3D CFD exergy analysis of the performance of a counter flow vortex tube", International Journal of Heat and Technology, 32(1-2), pp. 71-77 (2014).
20. Moffat, R.J. "Using uncertainty analysis in the planning of an experiment", Trans. ASME, J. Fluids Eng., 107, pp. 173-178 (1985).

\section{Biographies}

Seyed Ehsan Rafiee, Assistant Professor at Urmia University of Technology, was born in Kermanshah in 1985. He received his BS degree in Mechanical Engineering from Razi University in 2010, and his MS and $\mathrm{PhD}$ degrees in the same field (major in Energy Engineering), from Urmia University of Technology in 2012 and 2015, respectively. He is now an Assistant Professor in the Department of Mechanical Engineering at Urmia University of Technology, Urmia, Iran. His research interests include fluid mechanics and thermodynamics.

M. M. Sadeghiazad, Associate Professor at Urmia University of Technology, was born in Tabriz, Iran, in 1975. He received his BS degree in Mechanical En gineering from Tabriz University in 2000, and his MS and $\mathrm{PhD}$ degrees both in Electrical Engineering (major in Control Engineering) from the same university in 2005 and 2011, respectively. He is now an Associate Professor in the Department of Mechanical Engineering at Urmia University of Technology, Urmia, Iran. His research interests include fluid mechanics, thermodynamics, and artificial intelligence. 